\title{
CHILDREN'S PALLIATIVE CARE IN SOUTH AFRICA: AN URGENT NEED FOR AN EVIDENCE BASE
}

\author{
Laura Mary Campbell \\ Human Sciences Research Council, Durban
}

There is an urgent need to develop and/or expand palliative care for children in South Africa, and this editorial emphasises the scarcity of an evidence base on which to base clinical and operational decisions.

Children in Africa are more likely to face illness and death before the age of 5 years than anywhere else in the world. ${ }^{1}$ In South Africa, HIV infection is the leading cause of death among children aged less than 5 years, ${ }^{2}$ and there are approximately 300000 children living with HIVIAIDS. ${ }^{3}$

An essential tool in the spectrum of care offered to HIVinfected South African children is antiretroviral therapy (ART), and South Africa's children's ART programme is the largest in the world. ${ }^{3}$ Unfortunately, according to the national guidelines the programme currently reaches less than half of the children estimated to need ART. If the revised World Health Organization (WHO) guidelines for ART are considered, the proportion of children who need ART but are not accessing it is even greater. ${ }^{3}$

Paediatric wards in South African government hospitals are occupied predominantly by children with HIV and AIDS-related illnesses. ${ }^{4}$ Providing hospital care for HIV-infected children is extremely stressful for both health care providers and caregivers, and sick children may face demoralising cycles of repeated hospital admissions. The needs of very ill young children are many and complex, and may be overlooked in busy, overstretched health care facilities.

Furthermore, not all sick children reach a health care facility and therefore are cared for in their own homes, placing a heavy burden on families, communities and informal cadres of health care workers, such as homebased care workers. In an attempt to broaden health care coverage the South African government has adopted a home-based care strategy premised on the belief that families are in the best position, with support from homebased care workers, to deliver a continuum of holistic care from infection through illness and death. ${ }^{5}$

Holistic, ongoing care for very ill, dying and bereaved children and their families is situated within the emerging sub-specialty of paediatric palliative care, which focuses on achieving the best quality of life for children with lifethreatening illnesses and their families. ${ }^{6}$
Children's palliative care is especially important in an African context because it can be delivered by a range of health care providers (professional and nonprofessional) and can be delivered both in health care facilities and in the home.

In South Africa, a number of health care facilities, hospices, non-governmental organisations, universities and the Department of Health are already delivering and developing aspects of children's palliative care. The Hospice and Palliative Care Association of South Africa is affiliated to a wider African Palliative Care Association and has been active in children's palliative care, particularly in advocacy and education.

Some existing home-based interventions cover components of children's palliative care; however, palliative care in the form of a comprehensive framework that considers the holistic needs of the child and family is currently limited. In particular, current home-based care programmes may lack an element of support and supervision by professionally trained palliative care providers. ${ }^{7}$ Little attention has been paid to the effectiveness and sustainability of home-based care interventions in providing children's palliative care.

Research elsewhere in Africa shows that when a nurse-led community-based children's palliative care intervention is available there are increased referrals, increased prescriptions of essential drugs and improved compliance with treatment regimens. ${ }^{8,9}$ However, the findings from such studies cannot be directly transcribed to the South African context, where care of children is conducted by relatively unskilled homebased care workers, perhaps with little or no support from professionals trained in palliative care.

The marginalisation of palliative care research in Africa is well documented. Reasons given for this marginalisation include lack of skills and knowledge, professional isolation, poor patient accrual, high attrition, lack of agreement on outcome measures, and lack of a common language. ${ }^{10}$ There are also unique challenges in developing rigour in sampling design and in reporting. ${ }^{11}$ Importantly, there are ethical challenges to be considered when researching very sick children who are HIV infected. ${ }^{12-14}$ 
Given the numbers of children affected and the need for palliative care to reach large numbers, I advocate that providing an evidence base for children's palliative care must be a priority. Any research should consider including perceptions and experiences of both caregivers and children, and researchers must consider cultural, language and ethical issues.

\section{REFERENCES}

1. Albertyn R, Rode H, Millar AJW, Thomas J. Challenges associated with paediatric pain management in Sub Saharan Africa. Int J Surg 2009;7(2):91-93

2. Bradshaw $D$, Bourne $D$, Nannan N. What Are the Leading Causes of Death among South African Children? Tygerberg: Medical Research Council, 2003

3. Davies M, Keiser O, Technau K, et al. Outcomes of the South African National Antiretroviral Treatment Programme for children: The leDEA Southern African Collaboration. S Afr Med J 2009;99(10):730-737

4. Richter L, Chandan U, Rochat T. Improving hospital care for young children in the context of HIVIAIDS and poverty. J Child Health Care 2009;13(3):198-211.

5. Mabude ZA, Beksinska ME, Ramkissoon A, Wood S, Folsom M. A national survey of home-based care kits for palliative HIVIAIDS care in South Africa. AIDS Care 2008;20(8):931-937.

6. Liben S, Papadatou D, Wolfe J. Paediatric palliative care: Challenges and emerging ideas. Lancet 2008;371:852-864.

7. Uys LR. Evaluation of the integrated community-based home care model. Curationis 2001;24:75-82.

8. Amery JM, Rose CJ, Holmes J, Nguyen J, Byarugaba C. The beginnings of children's palliative care in Africa: Evaluation of a children's palliative care service in Africa. J Palliat Med 2009;12(11):1015-1021.

9. Craig P, Dieppe P, Macintyre S, Michie S, Nazareth I, Petticrew M. Developing and evaluating complex interventions: The new Medical Research Council guidance. BMJ 2008:337(a1655)

10. Powell RA, Downing J, Mwangi-Powell F, Radbruch L, Harding R. Advancing palliative care research in sub-Saharan Africa: From Venice to Nairobi. Eur J Palliat Care 2008;15(5):228-233

11. Bakitas M, Lyons K, Dixon J, Ahles T. Palliative care program effectiveness research: Developing rigor in sampling design, conduct, and reporting. J Pain Symptom Manage 2006;31(3):270-284

12. Tomlinson D, Bartels U, Hendershot E, Constantin J, Wrathall G, Sung L. Challenges to participation in paediatric palliative care research: A review of the literature. Palliat Med 2007;21:435-440.

13. Currow D, Wheeler J, Glare P, Kaasa S, Abernethy A. A framework for generalizability in palliative care. J Pain Symptom Manage 2008;37(3):373-386.

14. Allen D, Marshall ES. Children with HIVIAIDS: A vulnerable population with unique needs for palliative care. J Hospice Palliat Nurs 2008;10(6):359-367. 